Article

\title{
The Significance of Consumer's Awareness about Organic Food Products in the United Arab Emirates
}

\author{
Safdar Muhammad, Eihab Fathelrahman * and Rafi Ullah Tasbih Ullah \\ Department of Agribusiness and Consumer Sciences, College of Food and Agriculture, \\ United Arab Emirates University, P.O. Box 15551 Al Ain, UAE; smuhammad@uaeu.ac.ae (S.M.); \\ rafiullah.tasbih@uaeu.ac.ae (R.U.T.U.) \\ * Correspondence: eihab.fathelrahman@uaeu.ac.ae; Tel.: +971-03-713-4589
}

Academic Editor: Sean Clark

Received: 17 April 2016; Accepted: 10 August 2016; Published: 23 August 2016

\begin{abstract}
Awareness about negative externalities generated by conventional farming is gaining momentum with consumers around the world, opting for alternatively, namely organically, produced food products. Information about consumers' awareness is an essential element for farmers and marketing agencies to successfully plan production that can capture a greater market share. This study discusses effective factors influencing consumers' awareness about the benefits of organic food in the United Arab Emirates. Sample data and ordinary least square (OLS) regression techniques are applied to delineate factors influencing consumers' awareness about organic food. The results from this regression analysis highlight the importance of specific socioeconomic determinants that change awareness about organic food products in United Arab Emirates (UAE) households. This study finds that awareness about organic food is influenced more effective factors such as gender, nationality, and education as well as income, occupation and age. These research findings apply to other economies and societies that have an increasing per capita spending on organic food, but also where people are highly sensitive to information provided about organic food. Therefore, these results are important to these research beneficiaries including food marketing planners, researchers, and agricultural and food policy makers.
\end{abstract}

Keywords: organic food; consumers' awareness; effective socioeconomic characteristics; market segmentation

\section{Introduction}

Traditional or conventional farming is a double-edged sword; on one side it is known for low cost and higher output, but on the other side it is known for its negative human and environmental impacts [1]. The net effects of these factors are not yet known with certainty, but the negative impacts of inorganic farming and food products are well-researched. On the production side, farmers and their families, farm workers such as pesticide applicators, and other field workers are all at a high risk of exposure. Scialabba showed [2] in a study supported by the Food and Agriculture Organization (FAO) that sustainability is also about equity among and between generations. The main contribution of organic agriculture to social well-being is through avoided harm and healthy community development. Avoided harm ranges from loss of arable soil, water contamination, biodiversity erosion, food scares, and pandemics associated with chemical agriculture, as well as the pesticide poisoning of 3 million persons per year resulting in 220,000 deaths, let alone farmers' indebtedness for inputs and suicides (e.g., 30,000 deaths in Maharastra, India, from 1997 to 2005). Lotter (2003) found that demand for organic products is driven by belief that such products are more healthful, tasty, and environmentally friendly than conventional products [3]. Lotter also called for more comparative research to include animal products beside plant products. On the consumption side, the risk to consumers due to the 
consumption of vegetables at which high levels of synthetic pesticides have been applied is high because consumers are not aware of the health hazards linked to chemical residues in vegetables [4]. In a study by Salazar (2014) titled "Going Organic in Philippines: Social and Institutional Features", the author noticed — through case studies of organic farms and a review of policy developments-that different social arrangements and a supportive environment can be achieved. This is through offering training opportunities, expanding resource access, and organizational support leading to organic farming that expands exponentially in the country [5]. Golderger (2008) showed the presence of a disconnect between farmers and nongovernment organizations in Kenya, the source of organic agriculture organizations which attributed to the delay of farmers' adoption of organic agriculture practices [6].

Organic farming minimizes social, ecological, and biological costs that are associated with conventional farming [7]. Phillip and Dipeolu (2010) [8] defines organic farming to be the farming production management system which promotes agroecosystem health, sustainable biological cycles, and soil biological activity. In other words, organic farming is based on sustainability of the agroecosystem, Food and Agriculture Organization (FAO) [9]. Gil et al. (2000) [10] showed that among the different organic products market segments in Spain, special attention has to be paid to "likely consumers". Consumers represent a potential for market growth, and specific-marketing strategies should be addressed towards them. The authors conclude that a better knowledge of their sociodemographic characteristics is needed. On the demand side, Beharrell and McFie on British (1991) consumers and Al-Taie (2015) on United Arab Emirates consumers showed that such consumers have positive attitudes towards organic products as they perceive them as healthier than conventional alternatives [11,12].

The contribution of conventional agriculture to national development and food security has always been seen as the crux of public policy across the globe, yet in recent decades, organic agriculture has taken over conventional farming in terms of growth. For example, as shown in the Figure 1, organic agricultural land in the world increased from 11 million hectares in 1999 to 43.1 million hectares in 2013 [13]. Similarly, the number of organic producers also increased from 1.8 million in 2011 to 2 million in 2013 [13].

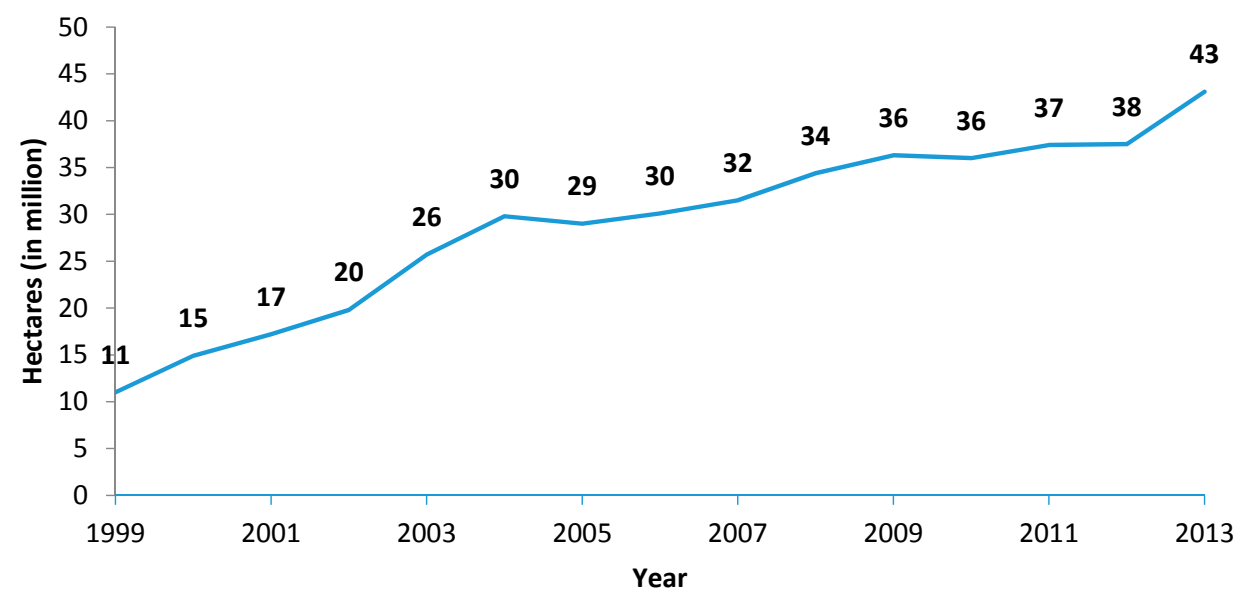

Figure 1. Growth of organic agricultural land in the world (1999-2013). Data Source: Willer et al., (2013) [13].

Zanoli and Naspetti (2002) [14] presented results from an Italian study on consumer perception and knowledge of organic food and related behavior. The authors used the means-end chain model to link attributes of products to the needs of consumers. The authors reported and discussed results on consumer cognitive structures at different levels of experience. In this study, consumers' groups were found to be due to the consumers' frequency of use (experience) of organic products and level of information (expertise). Müller et al. (2015) [15] studied the negative effects on consumers' 
evaluations of and behavior towards the purchase of certified organic food. The authors used behavioral models and findings from previous studies as well experimental study. The authors, highlighting the importance of consumers' awareness about organic food benefits, argued that when producers' mislabeling of products or consumers' label misinformation is revealed by mass media sources, such mislabeling causes negative effects on consumers' evaluation of and behavior towards the purchase of certified organic food products. These studies agreed that awareness about organic food benefits is an implicit variable. Other explicit variables-such as respondents' education, occupation, and age-were not carefully considered by these previous studies and were not considered to be effective variables to measure the consumers' level of awareness. In this study we argue for the significance of such variables and discuss the relationship between them and the consumers' awareness about organic products.

\section{Organic Products Market in United Arab Emirates}

In the United Arab Emirates (hereafter UAE), the agricultural sector has never been a major contributor to its gross domestic product (GDP). According to 2012 statistics from the Ministry of Environment and Water (MoEW) [15], agricultural land in the UAE constitutes only $4.6 \%$ of its total land. In addition, the value added per worker in the agricultural sector is merely USD 11,795, which is at a large decline since 2000 when this figure was nearly USD 30,000. However, given increasing income and the demand for fresh and healthier food products, agricultural development and food quality are major priorities of the UAE government agricultural policies [16]. These conditions provide an opportunity for organic agriculture to expand in the UAE. Table 1 shows data from 2012 about organic agricultural production in the UAE.

Table 1. Organic agriculture production (2012): selected characteristics in the United Arab Emirates.

\begin{tabular}{lc}
\hline Characteritics & Value \\
\hline Share of organic agricultural land & $4.6 \%$ \\
Organic agricultural land total & 3905 hectares \\
Share of organic agriculture in total & $0.7 \%$ \\
Number of certified organic farms & 34 \\
Number of certified organic crops & More than 62 varieties \\
\hline \multicolumn{2}{c}{ Source: Food and Agriculture Organization (FAO) (2013) [17]. }
\end{tabular}

Currently, the UAE market for organic food is valued at USD 100-150 million per year [16]. There are 34 certified organic farms producing more than 62 varieties of organically certified crops. While the UAE is one of the leading producers of organic palm dates (more than 1000 tons per year), it also produces organic vegetables, such as beans, beetroot, broccoli, cabbage, chilies, cucumber, eggplant, fennel, carrots, green peas, lettuce, marrows, onions, okra, potatoes, strawberries, sweet corn, and tomatoes [13].

Despite a considerable increase in the demand for organic products around the world [18], organic products are still considered specialty commodities in the food market and occupy a small market share, and there is an overall low market awareness about organic products. A successful campaign for introducing a new product into the market depends on two factors: consumer's awareness about the product and their willingness to pay $[19,20]$. Determinants influencing consumers' willingness to pay for organic food in the UAE has been addressed elsewhere [19]. The objective of this article is to evaluate factors that effectively influence the consumer's awareness about organic food in the UAE and recommend potential implications and marketing efforts needed to increase awareness about organic food in an effort to increase organic products' market share. The rest of the article is organized as follows. Section 2 describes the organic product market in United Arab Emirates (UAE). Section 3 summarizes lessons learned from previous studies on consumers' awareness about organic food products. Section 4 describes the methods used for data collection and the statistical analysis, 
as well as explains the selected dependent variable and explanatory variables. Section 5 presents and discusses empirical findings and Section 6 concludes with policy implications based on the application of the study's findings to food policy makers, researchers, and the organic food marketing planners.

\section{Consumer's Awareness about Organic Food}

Consumer's awareness refers to product characteristics exploration and recognition by consumers. This is the organic product's characteristics/attributes such as nutritional contents, whether the product is certified organic or not, locally produced or imported, country of origin (if it is imported), labeling information including date of expiration, and level of freshness. Furthermore, specific brands are likely to be considered by the consumers to have high quality organic products, so such consideration may affect his or her decision-making about purchasing a specific brand of food products $[12,20]$.

Chouichom et al. (2013) [21] investigated the impact of socioeconomic and demographic variables on organic food purchase behavior in Bangkok. Data was collected from 848 customers using convenient sampling. Since nonrandom sampling was used, the representativeness of the sample was insured by collecting data from customers who shop organic products from supermarkets, as well as from shops in the outskirts of Bangkok. Respondents were divided into three categories: those who have never heard of organic food, those who have heard but never purchased organic food, and those who have both heard and experienced consuming organic food. Then, contingency tables and chi-square tests were used to establish socioeconomic and demographic differences between the three types of consumers. According to the results reported by the authors, there are three main motives to demand organic food in Bangkok: the perceived health benefits, the search for tastier food, and attraction offered by novel food products. Moreover, statistical analysis signified that organic food consumption in Bangkok tends to increase with age, being male, education, and income.

Similarly, Bravo et al. (2013) [20] investigated various motives that encourage organic food consumption in Germany. Using data from the German National Nutrition Survey II, attitude towards organic food purchase is measured through the perceived importance of organic food. Results from the structural equation modeling (SEM) indicated that organic food purchases are influenced by altruistic aspects (i.e., environmental concerns and animal welfare). Additionally, nutritional information and ease of accessibility also positively influences organic food purchases, while price is negatively associated with organic food purchases. Amongst the socioeconomic and demographic variables, the authors reported that respondents from small households, women and older respondents, and those with higher societal status are more likely to purchase organic alternatives. Similar findings are also reported by Meixner et al. (2014) for Russia with the addition that consumers also prefer local foods, and that ease of access to organic food has no effect on consumers' purchasing behavior [22].

Briz and Ward (2009) [23] explored covariates of consumers' awareness in the case of Spain. Using a telephonic interview, the authors collected data from 1003 respondents, all of whom were above 18 years of age. Using multinomial logistic model, the dependent variable, i.e., awareness about organic food, was operationalized as having three categories. Explanatory variables of the model included age, education, income, gender and a general understanding of food nutrition (all are being measured as categorical variables). The authors also controlled for region and size of the city where the respondent belonged. Their results show that consumers' awareness about organic food is influenced only by the level of education, income and the degree by which a consumer is nutrition-conscious. That is, all the stated variables are positively associated with consumers' awareness about organic food. Theoretically, awareness about a product can be measured by using two techniques: brand recall and brand recognition. In brand recall tests, researchers measure the ability of consumers to recall brand names in a particular product category. In a brand recognition test, researchers provide consumers with a list of brands and ask them if they can remember seeing any of the brands before. For empirical studies, both techniques can be used to provide simple descriptions (i.e., average, range of response, mode, and standard deviation) or to provide more detail by using factor analysis [24]. Kesse-Guyot et al. (2013) [25] profiled organic food consumers in a 
large sample of French adults using cluster analysis and found that a sizable group of regular organic food consumers had shown a healthy profiles compared to nonorganic food consumers. However, the authors suggested further studies to analyze organic food intake in relation to health markers. A study that considered the demographic portrayal of organic vegetable consumption within the United States (U.S.) by Dettmann et al. (2007) [26] found that the organic market sector in the U.S. is one of the fastest growing food sectors, with growth rates in organic food sales averaging $18 \%$ per year between 1998 and 2005. The largest segment within the organic market was found to be fresh produce, comprising $36 \%$ of retail sales in 2005 . The study applied a logistic model framework and a Heckman two-stage model to depict the relationship of organic vegetable expenditures as a ratio of total household vegetable expenditures. The authors found that race, education level, and household income consistently influenced the consumer's decision to purchase organic vegetables.

In brief, previous studies discussed and analyzed the importance of consumers' awareness about organic food products at various settings and conditions. These conditions varied from local organic products to the overall organic food products including imported products. These previous studies agreed that the socioeconomic/demographic factors play significant roles on determining the consumers' decision to buy organic product. In this study we confirm previous studies summarized above. Furthermore, this study addresses and analyzes the influence of non-income and non-occupation status variables such as gender, education, and nationality as we argue that they could be more relevant to changes on the dependent variable (i.e., awareness about organic food products). Variables such as household income and occupation status are important to make the consumer demand an effective demand, so their inclusion in the econometric model specification is critical. However, this study's objective is to further analyze the significance of each of such on the non-income related explanatory (independent) variables towards the overall awareness of consumers about organic food products.

\section{Data and Methods}

The study is based on a sample survey of 300 respondents from the United Arab Emirates (UAE). The descriptive statistics of the respondents in the sample indicates that the typical respondent (median) of the head household in the sample is male, in the age category between 30 and 39 years old, married with children, completed his college education, originally non-national, works for the private sector, has income between 10,000 and 15,000 UAE Dirhams (exchange rate is 1 USD = 3.65 UAE Dirhams), and lives with a family of four members. The data was collected through a well-structured questionnaire, containing questions on awareness about organic food and sociodemographic information of the respondents. The questionnaire for this study was designed to solicit the respondents about their level of awareness about organic food products, organic food market characteristics, and their ranking for the importance of organic food features such as their perception of whether they consider organic food product to be chemical-free, fresh and healthy, better-tasting or not, was produced used best agricultural production practices, among many other attributes. The questionnaire in this study was divided into two parts. Part one asked questions in relation to the respondents' perception and attitudes towards organic products in UAE, including questions about the frequency of buying organic food, and positive and negative attributes of buying organic food. For example, the questionnaire asked if the respondents considered organic food to be expensive, whether they still purchase the products due to the benefits they draw from consumption of organic food. This part also included questions in relation to respondent's level of trust of organic food certification in UAE and other places. The second part of the questionnaire included questions about the respondents' socioeconomic or demographic variables. These questions enable the research to draw conclusions about the correlations between such explanatory variables on one side and the research-dependent variable, namely awareness about organic food.

Awareness can be measured by asking simple descriptive questions from the respondents, using factor analysis (FA)/principle component analysis (PCA). 
To depict factors influencing consumer's awareness about organic food in the UAE, we used the following:

$$
A W_{i}=\beta_{0}+\beta_{1} A G_{i}+\beta_{2} G R_{i}+\beta_{3} N Y_{i}+\beta_{4} E D_{i}+\beta_{5} M I_{i}+\beta_{6} E S_{i}+\beta_{7} H S_{i}+\epsilon_{i}
$$

The dependent variable is awareness about organic food (AW), which is an index constructed from various awareness indicators asked from respondents. Based on similar a principal component analysis by Qendro (2015) [27] and Petrrescu et al. (2015) [28], we have asked respondents questions like, "Do you consume organic food because you think it is chemical free?" Responses were recorded for a total of 17 such questions in the form of 0 (which implies no) and 1 (which implies yes). Each of the 17 questions highlighted a key characteristic of organic food, such as freshness, taste, and nutrients. To construct our dependent variable, we have adopted the simple counting procedure which adds responses to all questions (Lea, and Worsley, 2005) [29] for adopting a similar methodology to develop the index of awareness variables. On the explanatory variables side, a set of variables were included to represent the respondents' socioeconomic characteristics. These variables are namely Age, Gender, Nationality, Education, Monthly income, Employment status, and Household size.

As a robustness check of our awareness measure, we have also constructed another measure of awareness about organic food. One of the questions in the survey asked respondents, "How much have you heard or read about organic food?" Responses to the questions were recorded on a 4 point Likert scale (i.e., $1=$ nothing at all, $2=$ a little, $3=$ some, and $4=$ a lot). We have considered options 1 and 2 as respondents who are unaware or less aware about organic food and the remaining two options as respondents who possess awareness about organic food. Since the dependent variable thus constructed is a dichotomous one, the estimation technique adopted for the purpose is binary logistic model. The results obtained are given in Appendix 6, which show that none of the explanatory variables assume signs different from the main model, nor are these much different in magnitude. As a further robustness check, the awareness variable is also specified as standard normal scores (Appendix 6) and the results resemble the original ones.

AG is the age of the respondent, which is a multinomial variable having five categories: 1 signifies age younger than 20 years of age, 2 between 20 and 29 years of age, 3 between 30 and 39 years of age, 4 between 40 and 49 years of age, and 5 greater or equal to 50 years of age. A dichotomous variable representing gender is named GR, where 1 represents male and 0 female. The dichotomous variable, NY representing nationality, where 1 represents a UAE resident and 0 otherwise. The respondent's education level, ED, has six categories, where 1 represents the lowest level of education and 6 the highest. MI is the monthly income of the respondents and has 7 categories, where 1 is the lowest income level and 7 is the highest income level. Meanwhile, ES is a dichotomous variable representing the employment status of the respondent, where 1 represents those who are actively employed (e.g., government employees, self-employed, and private sector employees) and 0 represents those who are not active participants in the job market (e.g., retired, housewives, student, unemployed, and others). Finally, HS represents the number of people living in the household, including the respondent.

Since the dependent variable in Equation 1 is a continuous variable, the appropriate estimation method is ordinary least squares (OLS), provided that the basic Gauss-Markov properties are satisfied. The model is thus tested for multi-collinearity, heteroskedasticity, and misspecification. All tests confirmed that the model does not suffer from any of the above stated sources of biases. The following section presents and discusses the results.

\section{Results and Discussion}

To study the relationship between the consumers' awareness about organic food and their socioeconomic characteristics. The ordinary least square (OLS) regression was selected to illustrate and predict such a relationship. The estimated outputs of Equation 1 are presented in Table 2. The equation was estimated using the OLS method and the results were checked for multicollinearity (using variance 
inflating factor criteria), heteroskedasticity (using White's heteroskedasticity test), and misspecification errors (using Ramsey's RESET test) (given in Appendix 6). Since the results satisfy these tests, we can safely conclude that our results are free from any econometric bias. The best fit curve of this model is depicted in Figure 2.

Table 2. Awareness about organic food.

\begin{tabular}{ccccc}
\hline Variable & Coefficient & Std. Error & T-Statistics & $p$-Value \\
\hline Age & -0.189 & 0.274 & -0.691 & 0.490 \\
Gender & $1.055^{* *}$ & 0.538 & 1.959 & 0.051 \\
Nationality & $1.631^{* *}$ & 0.731 & 2.232 & 0.027 \\
Education & $0.658^{* *}$ & 0.277 & 2.376 & 0.018 \\
Monthly income & -0.134 & 0.145 & -0.919 & 0.359 \\
Employment status & -0.025 & 0.647 & -0.039 & 0.969 \\
Household size & -0.013 & 0.063 & -0.213 & 0.832 \\
Constant & $3.449^{* *}$ & 1.793 & 1.924 & 0.055 \\
\hline
\end{tabular}

** signifies statistical significance at 5 percent level.

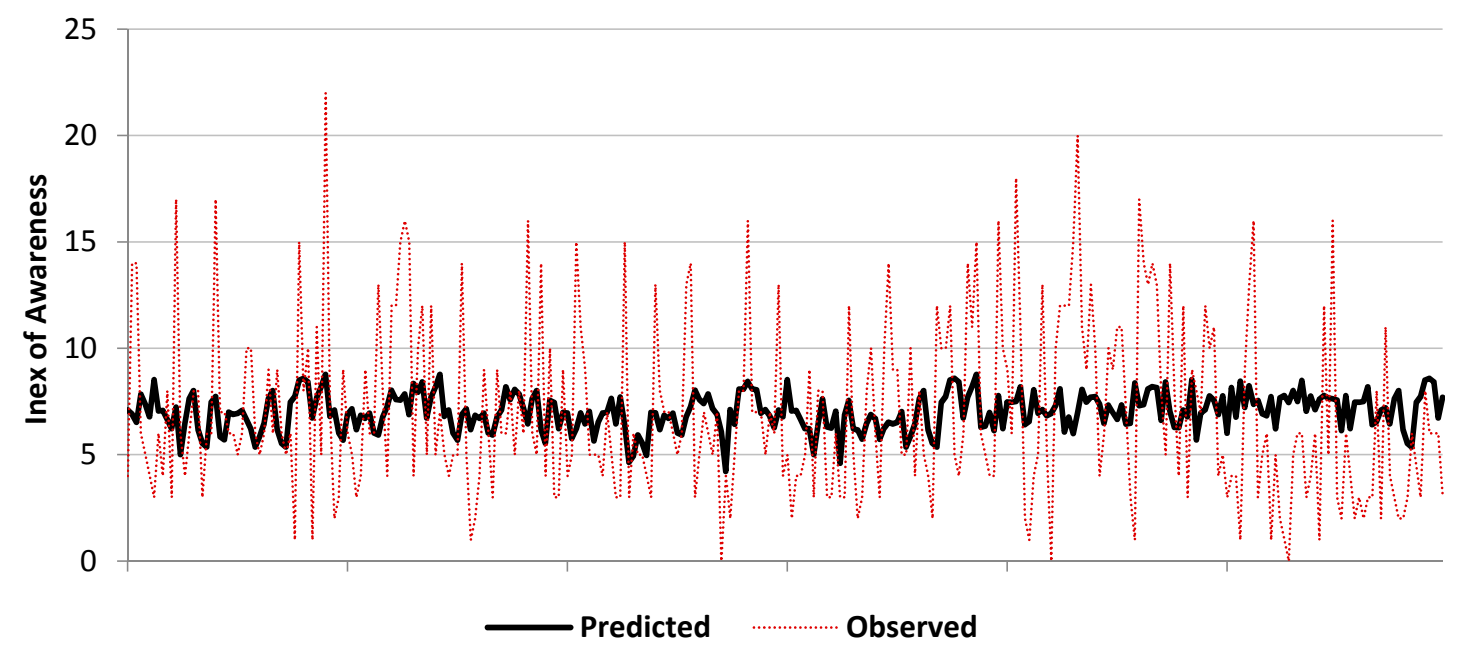

Figure 2. Predicted awareness index against observed levels of awareness about organic agriculture in United Arab Emirate.

The results show that of all the explanatory variables analyzed in our study, only gender, nationality, and education influence awareness about organic food positively. Because none of the other explanatory variables are statistically significant, we ignore them in the subsequent discussion. However, these variables are important for the overall econometric model design and fitness representing the dataset. An explanation for why gender is a significant explanatory variable is that male respondents have more awareness about organic food than their female counterparts. This finding is in line with previous research cited in the previous section of this article. These studies noted that the reason behind more organic food awareness among male members is because overall, male members are relatively more educated in developing countries where these studies are conducted. The correlation matrix illustrated in Appendix 6 shows the correlation between the explanatory variables (independent variables) themselves. No evidence found of highly significance correlation between these variables which supports selection of these variables to be possible influential variables on the level of the respondents' awareness of organic products in the study sample.

The results also found that being a national of the UAE increases awareness about organic food. An explanation for this is that the majority of non-UAE nationals are immigrants who are low-paid workers lacking education and circles that can provide them awareness about organic food. 
The positive and significant impact of education on awareness about organic food implies that more education increases awareness about organic food. There is a strong connection between education and awareness of organic food benefits, including the environmental benefits of production (the supply side) and consumer health benefits (the demand side). These results confirmed previous studies' findings and highlight the significance of more relevant (to the level of awareness about organic food) explanatory (independent) variables in the study such as the consumer's gender, level of education, and nationality. Furthermore, study findings show that such respondents' effective explanatory (independent) variables play a significant role on increasing awareness about organic products. Policy makers, researchers, and marketing analysts may consider such significant variables when designing their organic products' market share.

\section{Conclusions and Recommendations}

A key challenge faced by the modern world is food security. Conventional farming may be considered a success in the quest for food security, but it comes at the cost of the overall well-being of the environment and ecosystem. Organic farming is a relatively new system of farming; it avoids costs associated with conventional farming and it is considered beneficial for the planet as a whole. Because organic farming is relatively new, the perceived benefits associated with it are not well-known. It will take time and effort for its benefits to become common knowledge.

Increasing awareness about the benefits of organic food compared to conventionally-produced food is relatively expensive. Therefore, awareness about the advantages of organic agriculture has not been well-considered in previous studies as an approach for sustainable production and consumption. In order to encourage organic farming and the production of organic food, the market for organic food will have to be established, so that organic farmers can get an outlet for their products. However, the establishment of a market for organic food depends on knowing what factors influence consumer awareness about organic food. Once such factors are ascertained, farmers will be better equipped to market their organic products and capture a larger share of the vegetable market. This study is an attempt to identify factors that determines consumers' awareness about organic food. This study utilizes sample data and contemporary econometric techniques to investigate factors that influence consumers' awareness about organic food. Furthermore, this study implements an ordinary least square (OLS) analysis of consumers' income, occupation status, and age as determinants of the level of consumers' awareness about organic food products. Furthermore, the study expanded the analysis to include more relevant explanatory variables such as gender, education, and nationality in order to better explain the influence of such non-income variables on consumers' awareness about organic food products. Income and occupation status are effective demand variables. Both variables contribute to the overall fitness of the regression model. However, specific variables such as gender, respondents' level of education, and nationality were found to be more significant.

This study finds that awareness about organic food is influenced by more relevant factors such as gender, nationality, and education as well as income, occupation status, and age. Therefore, efforts to successfully expand awareness about organic foods should consider nonconventional socioeconomic/demographic characteristics of consumers when segmenting markets. Understanding of the significance of the influential factors that determine the consumers' decision of buying organic food helps the policy makers, researchers, and marketing planners focus their efforts and expand them in the areas of providing the consumers with more information in relationship to the products' characteristics and designing awareness activities about organic food production, consumption, and health benefits. Such effort will support the organic farmers' in gaining larger market shares for their products.

Future studies may consider the need for comprehensive framework to support organic products marketing including policy formulation, research, education, and outreach to support the organic food production. Furthermore, future studies may also consider changes of consumers' behavior in response to expanding use of information through advanced information technology such as social media. 
Author Contributions: All the authors contributed equally to this work.

Conflicts of Interest: The authors declare no conflict of interest.

\section{Appendix A}

Table A1. Awareness about Organic Food (Logistic Regression).

\begin{tabular}{ccccc}
\hline Variable & Coefficient & Std. Error & Wald & Significance \\
\hline Age & -0.052 & 0.311 & 0.028 & 0.867 \\
Gender & 0.334 & 0.286 & 1.368 & 0.242 \\
Nationality & 0.093 & 0.366 & 0.065 & 0.799 \\
Education & 0.059 & 0.458 & 0.016 & 0.898 \\
Monthly income & -0.382 & 0.324 & 1.395 & 0.237 \\
Employment status & -0.069 & 0.323 & 0.045 & 0.832 \\
Household size & -0.003 & 0.033 & 0.011 & 0.918 \\
Constant & 0.838 & 0.722 & 1.349 & 0.245 \\
\hline
\end{tabular}

\section{Appendix B}

Table B1. Awareness about Organic Food (Awareness Specified as Standard Normal Scores).

\begin{tabular}{ccccc}
\hline Variable & Coefficient & Std. Error & $t$-Statistics & $p$-Value \\
\hline Age & -0.046 & 0.066 & -0.691 & 0.490 \\
Gender & 0.255 & 0.130 & 1.959 & 0.051 \\
Nationality & 0.395 & 0.177 & 2.232 & 0.027 \\
Education & 0.159 & 0.067 & 2.376 & 0.018 \\
Monthly income & -0.032 & 0.035 & -0.919 & 0.359 \\
Employment status & -0.006 & 0.157 & -0.039 & 0.969 \\
Household size & -0.003 & 0.015 & -0.213 & 0.832 \\
Constant & -0.861 & 0.434 & -1.984 & 0.048 \\
\hline
\end{tabular}

\section{Appendix C. Diagnostic Tests}

Table C1. Collinearity test.

\begin{tabular}{ccc}
\hline Variable & Tolerance & Variance Inflation Factor \\
\hline Age & 0.842 & 1.188 \\
Gender & 0.941 & 1.062 \\
Nationality & 0.610 & 1.639 \\
Education & 0.879 & 1.138 \\
Monthly income & 0.687 & 1.455 \\
Employment status & 0.657 & 1.522 \\
Household size & 0.938 & 1.067 \\
\hline
\end{tabular}

Table C2. Heteroskedasticity test.

\begin{tabular}{|c|c|c|c|}
\hline \multicolumn{4}{|c|}{ White Heteroskedasticity Test } \\
\hline F-Statistics & 1.414 & Probability & 0.167 \\
\hline R-Squared & 15.338 & Probability & 0.167 \\
\hline
\end{tabular}




\section{Appendix D}

Table D1. Correlation Matrix.

\begin{tabular}{|c|c|c|c|c|c|c|c|c|}
\hline & & $\begin{array}{l}\text { Age of the } \\
\text { Respondent } \\
\text { (Original) }\end{array}$ & $\begin{array}{l}\text { Gender of the } \\
\text { Respondent }\end{array}$ & $\begin{array}{l}\text { Nationality of } \\
\text { the Respondent }\end{array}$ & $\begin{array}{c}\text { Education of } \\
\text { the Respondent } \\
\text { (Original) }\end{array}$ & $\begin{array}{l}\text { Income of the } \\
\text { Respondent } \\
\text { (Original) }\end{array}$ & $\begin{array}{l}\text { Employment } \\
\text { Status of the } \\
\text { Respondents }\end{array}$ & $\begin{array}{l}\text { Household } \\
\text { Size }\end{array}$ \\
\hline \multirow{2}{*}{$\begin{array}{l}\text { Age of the } \\
\text { respondent } \\
\text { (Original) }\end{array}$} & $\begin{array}{c}\text { Pearson } \\
\text { Correlation }\end{array}$ & \multirow[t]{2}{*}{1} & 0.032 & $-0.209^{* *}$ & $-0.247^{* *}$ & 0.096 & $0.387^{* *}$ & -0.054 \\
\hline & Sig. (2-tailed) & & 0.585 & 0.000 & 0.000 & 0.120 & 0.000 & 0.356 \\
\hline \multirow{2}{*}{$\begin{array}{l}\text { Gender of the } \\
\text { respondent }\end{array}$} & $\begin{array}{l}\text { Pearson } \\
\text { Correlation }\end{array}$ & 0.032 & \multirow[t]{2}{*}{1} & -0.068 & -0.031 & 0.056 & $0.250^{* *}$ & -0.077 \\
\hline & Sig. (2-tailed) & 0.585 & & 0.237 & 0.588 & 0.369 & 0.000 & 0.187 \\
\hline \multirow{2}{*}{$\begin{array}{l}\text { Nationality of } \\
\text { the Respondent }\end{array}$} & $\begin{array}{c}\text { Pearson } \\
\text { Correlation }\end{array}$ & $-0.209 * *$ & -0.068 & \multirow[t]{2}{*}{1} & -0.107 & $0.442 * *$ & $-0.329 * *$ & 0.137 * \\
\hline & Sig. (2-tailed) & 0.000 & 0.237 & & 0.063 & 0.000 & 0.000 & 0.018 \\
\hline \multirow{2}{*}{$\begin{array}{l}\text { Education of the } \\
\text { respondent } \\
\text { (original) }\end{array}$} & $\begin{array}{c}\text { Pearson } \\
\text { Correlation }\end{array}$ & $-0.247^{* *}$ & -0.031 & -0.107 & \multirow[t]{2}{*}{1} & 0.040 & $-0.254^{* *}$ & $-0.119 *$ \\
\hline & Sig. (2-tailed) & 0.000 & 0.588 & 0.063 & & 0.523 & 0.000 & 0.041 \\
\hline \multirow{2}{*}{$\begin{array}{l}\text { Income of the } \\
\text { respondent } \\
\text { (Original) }\end{array}$} & $\begin{array}{c}\text { Pearson } \\
\text { Correlation }\end{array}$ & 0.096 & 0.056 & $0.442^{* *}$ & -0.040 & \multirow[t]{2}{*}{1} & $0.138^{*}$ & 0.097 \\
\hline & Sig. (2-tailed) & 0.120 & 0.369 & 0.000 & 0.523 & & 0.026 & 0.119 \\
\hline \multirow{2}{*}{$\begin{array}{l}\text { Employment } \\
\text { status of the } \\
\text { respondents }\end{array}$} & $\begin{array}{c}\text { Pearson } \\
\text { Correlation }\end{array}$ & $0.387^{* *}$ & $0.250^{* *}$ & $-0.329^{* *}$ & $-0.254^{* *}$ & 0.138 * & \multirow[t]{2}{*}{1} & -0.074 \\
\hline & Sig. (2-tailed) & 0.000 & 0.000 & 0.000 & 0.000 & 0.026 & & 0.216 \\
\hline \multirow{2}{*}{ Household Size } & $\begin{array}{c}\text { Pearson } \\
\text { Correlation }\end{array}$ & -0.054 & -0.077 & $0.137 *$ & $-0.119 *$ & 0.097 & -0.074 & \multirow[t]{2}{*}{1} \\
\hline & Sig. (2-tailed) & 0.356 & 0.187 & 0.018 & 0.041 & 0.119 & 0.216 & \\
\hline
\end{tabular}

${ }^{* *}$ Correlation is significant at the 0.01 level (2-tailed). ${ }^{*}$ Correlation is significant at the 0.05 level (2-tailed). 


\section{References}

1. Lumpkin, H. Organic Vegetable Production: A Theme for International Agricultural Research. In Proceedings of the Seminar on Production and Export of Organic Fruit and Vegetables in Asia, Bangkok, Thailand, 3-5 November 2003.

2. Scialabba, N.E.-H. Organic Agriculture's Contribution to Sustainability. In Proceedings of the USDA Organic Farming Systems Research Conference, Washington, DC, USA, 29 April 2013.

3. Lotter, D.W. Organic agriculture. J. Sustain. Agric. 2003, 21, 59-128. [CrossRef]

4. Coulibaly, O.; Cherry, A.; Nouhoheflin, T.; Aitchedji, C.; Al-Hassan, R. Vegetable producer perceptions and willingness to pay for biopesticides. J. Veg. Sci. 2007, 12, 27-42. [CrossRef]

5. Salazar, R.C. Going organic in the Philippines: Social and institutional features. Agroecol. Sustain. Food Syst. 2014, 38, 199-229. [CrossRef]

6. Goldberger, J.R. Diffusion and adoption of non-certified organic agriculture: a case study from semi-arid Makueni District, Kenya. J. Sustain. Agric. 2008, 32, 531-564. [CrossRef]

7. Koocheki, A. Organic farming in Iran. In Proceedings of the 6th IFOAM-Asia Scientific Conference, Benign Environment and Safe Food, Yangpyung, Korea, 7-11 September 2004.

8. Phillip, B.; Dipeolu, A. Willingness to pay for organic vegetables in Abeokuta, South West Nigeria. Afr. J. Food Nutr. Sci. 2010, 10, 11. [CrossRef]

9. Food and Agriculture Organization (FAO) of the United Nations. Organic Agriculture: What Are the Environmental Benefits of Organic Agriculture? Available online: http://www.fao.org/organicag/oa-faq/ oa-faq6/en/ (accessed on 1 October 2015).

10. Gil, J.M.; Gracia, A.; Sanchez, M. Market segmentation and willingness to pay for organic products in Spain. Int. Food Agribus. Manag. Rev. 2000, 3, 207-226. [CrossRef]

11. Beharrell, B.; MacFie, J. Consumer attitudes to organic foods. Br. Food J. 1991, 93, 25-30. [CrossRef]

12. Al-Taie, W.A.; Rahal, M.K.; AL-Sudani, A.S.; AL-Farsi, K.A. Exploring the Consumption of Organic Foods in the United Arab Emirates. SAGE Open 2015. [CrossRef]

13. Willer, H.; Lernoud, J.; Home, R. The World of Organic Agriculture. Statistics and Emerging Trends 2013: Summary. Available online: http:/ /www.organic-world.net/yearbook/yearbook-2013.html (accessed on 22 August 2016).

14. Zanoli, R.; Naspetti, S. Consumer motivations in the purchase of organic food: A means-end approach. Br. Food J. 2002, 104, 643-653. [CrossRef]

15. Müller, C.E.; Gaus, H. Consumer response to negative media information about certified organic food products. J. Consum. Policy 2015, 38, 387-409. [CrossRef]

16. Ministry of Environment and Water (MoEW). UAE State of Green Economy; Ministry of Environment and Water (MoEW): Dubai, UAE, 2014.

17. Food and Agriculture Organization (FAO). FAOSTAT. Available online: http://faostat.fao.org/site/377/ default.aspx\#ancor (accessed on 10 October 2015).

18. Aryal, K.P.; Chaudhary, P.; Pandit, S.; Sharma, G. Consumers' willingness to pay for organic products: A case from Kathmandu valley. J. Agric. Environ. 2009, 10, 15-26. [CrossRef]

19. Muhammad, S.; Fathelrahman, E.; Ullah, R.U. Factors Affecting Consumers' Willingness to Pay for Certified Organic Food Products in United Arab Emirates. J. Food Distrib. Res. 2015, 46, 37-45.

20. Bravo, C.P.; Cordts, A.; Schulze, B.; Spiller, A. Assessing determinants of organic food consumption using data from the German National Nutrition Survey II. Food Qual. Preference 2013, 28, 60-70. [CrossRef]

21. Chouichom, S.; Liao, L.M.; Yamao, M. General View Point, Perception and Acceptance of Organic Food Products among Urban Consumers in the Thai Marketplace. In Sustainable Food Security in the Era of Local and Global Environmental Change; Springer: Berlin, Germany, 2013; pp. 187-201.

22. Meixner, O.; Haas, R.; Perevoshchikova, Y.; Canavari, M. Consumer Attitudes, Knowledge, and Behavior in the Russian Market for Organic Food. Int. J. Food Syst. Dyn. 2014, 5, 110-120.

23. Briz, T.; Ward, R.W. Consumer awareness of organic products in Spain: An application of multinominal logit models. Food Policy 2009, 34, 295-304. [CrossRef]

24. Keller, K.L. Conceptualizing, measuring, and managing customer-based brand equity. J. Mark. 1993, 57, 1-22. [CrossRef] 
25. Kesse-Guyot, E.; Peneau, S.; Mejean, C.; de Edelenyi, F.S.; Galan, P.; Hercberg, S.; Lairon, D. Profiles of organic food consumers in a large sample of French adults: results from the nutrinet-santé cohort study. PLoS ONE 2013, 8, e76998. [CrossRef] [PubMed]

26. Dettmann, R.L.; Dimitri, C. Organic consumers: A demographic portrayal of organic vegetable consumption within the United States. In Proceedings of the EAAE International Marketing and International Trade of Quality Food Products Meeting, Bologna, Italy, 8-10 March 2007.

27. Qendro, A.-E. Albanian and UK Consumers' Perceptions of Farmers' Markets and Supermarkets as Outlets for Organic Food: An Exploratory Study. Sustainability 2015, 7, 6626-6651. [CrossRef]

28. Petrescu, D.C.; Petrescu-Mag, R.M. Organic Food Perception: Fad, or Healthy and Environmentally Friendly? A Case on Romanian Consumers. Sustainability 2015, 7, 12017-12031. [CrossRef]

29. Lea, E.; Worsley, T. Australians' organic food beliefs, demographics and values. Br. Food J. 2005, 107, 855-869. [CrossRef]

(C) 2016 by the authors; licensee MDPI, Basel, Switzerland. This article is an open access article distributed under the terms and conditions of the Creative Commons Attribution (CC-BY) license (http://creativecommons.org/licenses/by/4.0/). 